\title{
Las vidas de Janus Jean Lurçat y el Museo de la Solidaridad ${ }^{1}$
}

\section{The Lives of Janus Jean Lurçat and the Museo de la Solidaridad}

\author{
Josefina de la Maza Chevesich \\ Centro de Investigaciones en Artes y Humanidades (CIAH), \\ Facultad de Artes, Universidad Mayor \\ josefina.delamaza@umayor.cl
}

\section{Resumen}

En 1972 llegó a Chile un tapiz titulado Janus (ca. 1960) del artista francés Jean Lurçat (1892-1966). La donación de la obra, realizada probablemente por su viuda, respondía a la convocatoria emitida un año antes por la comisión organizadora de un proyecto destinado a apoyar la vía chilena al socialismo: el Museo de la Solidaridad. Janus es el único tapiz de la colección del museo. A partir de una breve revisión de la relevancia de la tapicería pictórica francesa de la primera mitad del siglo xx y su presencia oblicua en el contexto chileno, este texto presenta la vida de esta obra en relación con los primeros meses de vida del Museo de la Solidaridad y su posterior existencia en Chile tras el golpe de Estado en 1973.

Palabras clave: Lurçat, tapiz, solidaridad, exposiciones.

\section{Abstract}

In 1972 a tapestry titled Janus (ca.1960) made by French artist Jean Lurçat (1892-1966) arrived in Chile. The donation, probably made by his widow, echoed the call for a project conceived to support the Chilean way to socialism: The Museum of Solidarity. Janus is the only tapestry of the museum's collection. Having as a starting point a brief review of the relevance of the French pictorial tapestry movement during the first half of the $20^{\text {th }}$ century and its oblique presence in the Chilean context, this text introduces the life of this artwork in relation to the organization of the Museum of Solidarity and its subsequent existence after the coup d'état in 1973.

Keywords: Lurçat, tapestry, solidarity, exhibitions.

1 Este texto formó parte del proyecto curatorial Tejido social. Arte textil y compromiso político (Museo de la Solidaridad Salvador Allende, marzo 2019-enero 2020). Asimismo, fue escrito en el contexto del proyecto de iniciación de la Vicerrectoría de Investigación de la Universidad Mayor, Artistas y artesanas: circulación de saberes y prácticas textiles en el siglo XIX chileno (2018-2019). La autora agradece los comentarios y sugerencias de Federico Brega, Soledad García, María José Lemaitre, Caroll Yasky e Ignacio Ramos. 
El 27 de abril de 1972, el Museo de Arte Contemporáneo (MAC) de la Universidad de Chile, situado en el antiguo Partenón de la Quinta Normal de la ciudad de Santiago, recibió una obra llegada recientemente desde el extranjero (IAL 11). La pieza provenía de Aubusson, una comuna de la región de Creuse en el centro de Francia, históricamente conocida por el trabajo en tapicería. ${ }^{2}$ El autor de la obra era Jean Lurçat, un artista francés asociado al surrealismo que, después de la Primera Guerra Mundial, incursionó en la elaboración de cartones para la fabricación de tapices, convirtiéndose con el paso de los años en una de las figuras más destacadas del proceso de revitalización de la llamada "tapicería pictórica" francesa de la primera mitad del siglo xx (Gardner Troy 164).

La obra de Lurçat era, como es de esperar, un tapiz: Janus había sido probablemente enviado a Chile por Simone Lurçat (1915-2009), viuda del artista, quien desde 1960 se había dedicado exclusivamente a promover la labor de su marido. Si bien la obra fue recibida en el MAC, su destino final era el Museo de la Solidaridad, institución que a la fecha no contaba con un espacio propio. El tapiz, de hecho, llegó a Chile de modo particular (es decir, no fue parte de un envío oficial) al año de lanzada la convocatoria para crear, en Santiago, un museo que apoyara desde las artes la vía chilena al socialismo. La iniciativa para crear el Museo de la Solidaridad surgió en el contexto de la "Operación Verdad”. En abril de 1971, el gobierno de Salvador Allende reunió en la capital a artistas, intelectuales y políticos extranjeros para combatir los ataques al Gobierno realizados por la oposición nacional e internacional y canalizados a través de la prensa. En ese encuentro, se reunió el crítico de arte español José María Moreno Galván, el senador italiano Carlo Levi, el crítico de arte brasileño Mario Pedrosa y el artista chileno José Balmes. El resultado de sus conversaciones fue el convencimiento de que "por medio de donaciones de obras de reconocidos artistas del mundo, se formaría un Museo de Arte Moderno y Experimental que sería el ejemplo concreto de la fraternidad artística" (Macchiavello 33). Era a esta convocatoria que respondía el envío de la obra.

Jean Lurçat había muerto cinco años antes, en 1966; unos años después, en 1971, Pablo Neruda fue nombrado embajador de Chile en Francia. Es posible que la presencia del poeta en París haya contribuido a los deseos de la viuda de realizar la donación, recordando la admiración mutua que existía entre Lurçat y Neruda. En 1954 Lurçat diseñó el tapiz Le chant général en honor al Canto General de Neruda (1950), el mismo año en que también realizó Hommage aux morts de la résistance et de la déportation. Neruda, por su parte, recordaba a Lurçat en diciembre de 1972 (cuando la obra ya se encontraba en Chile) como uno de sus camaradas entre los artistas comunistas, como un "tapicero de genio" (Teitelboim 475). Desde un punto de vista más íntimo, pero también considerando un registro político, es probable que Simone Lurçat donara Janus al pueblo de Chile honrando el inicio de su historia compartida: la pareja se había conocido cuando ambos trabajaban, durante la Segunda Guerra Mundial, para

2 Desde el 2009, Aubusson es un sitio protegido como Patrimonio Cultural Inmaterial de la Humanidad por la unEsco. 


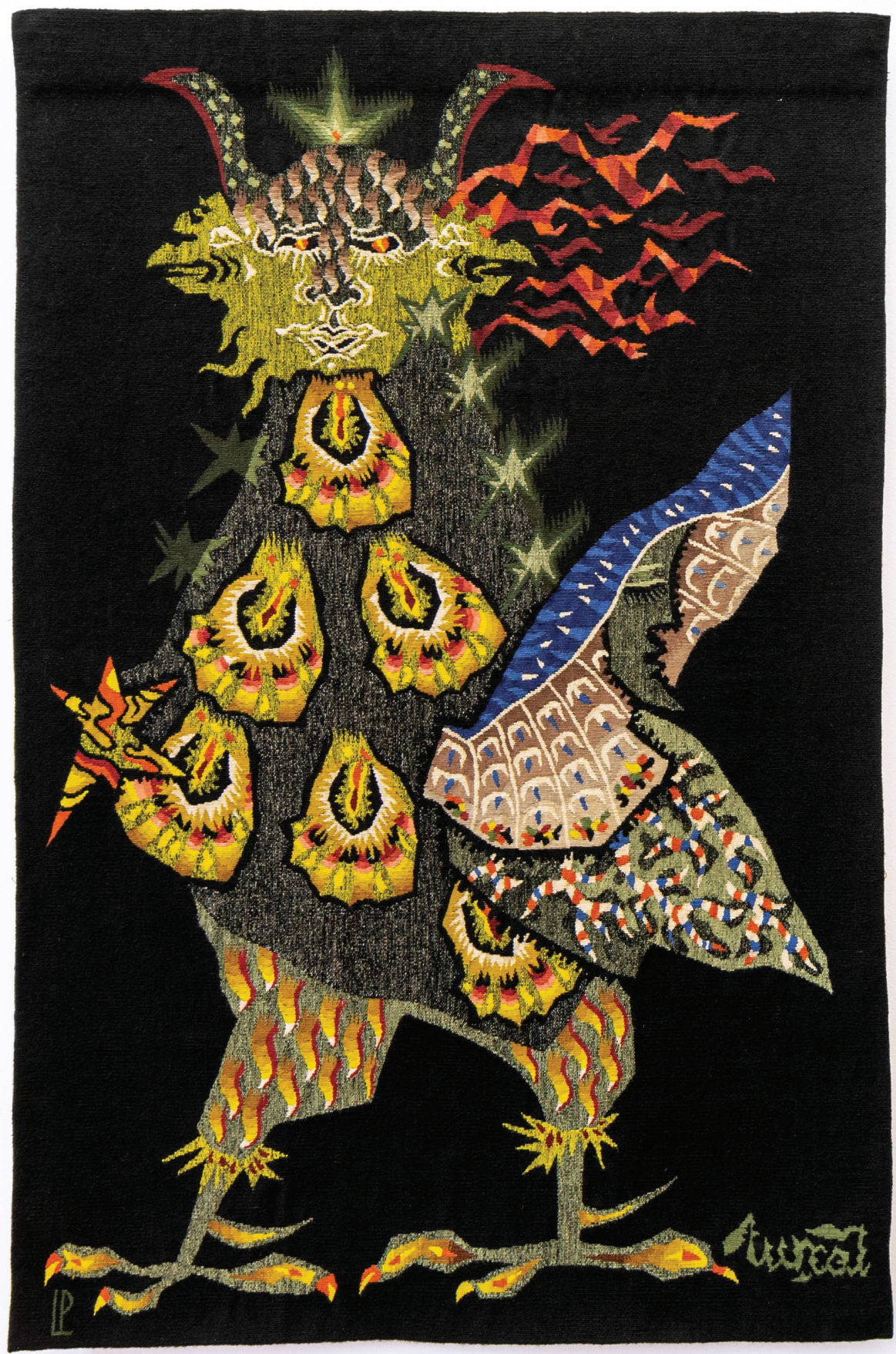

Jean Lurçat. Janus, 1964, tapicería enlazada, $148 \times 100 \mathrm{~cm}$.

Colección: Museo de la Solidaridad Salvador Allende (MSSA), Santiago

Créditos fotográficos: Benjamín Matte 
la resistencia. ${ }^{3}$ No sería equivocado suponer que el reciente fallecimiento del artista y las memorias de la guerra y de la lucha contra el fascismo hayan estado presentes en la decisión de donar una obra que apoyara el proyecto de Allende.

Además del entusiasmo por el proyecto político chileno, Lurçat ya tenía vínculos previos con el país, cuestión que también puede haber contribuido a la decisión de su viuda de donar la obra. Entre fines de 1954 y principios de 1955, el MAC había presentado una exposición individual de su trabajo, la que incluyó treinta tapices y más de cien pinturas, cerámicas y libros ilustrados (Fontaine et al.). La exposición viajaba desde Lima, en donde había sido muy bien recibida. En un recuento de las exposiciones del año, un crítico peruano comentaba:

Todo lo que en el genio nacional francés hay de belleza y mesura, delicada captación de los matices, refinamiento en el oficio y verdad en la expresión, estaba presente en los bellísimos tapices de Aboussón [sic] que nos visitaron. Fue aquello una fiesta para el espíritu, así como una lección de verdad artística. [...] Una tradición artesanal mantenida siempre viva, fresca en sus innovaciones, limitada en sus audacias por la trama, pero vivaz y caprichosa [...] (Ugarte Eléspuru s. p).

El éxito en Santiago fue similar. En la Revista de Arte, por ejemplo, se comentó el éxito de asistencia a la exposición: según los registros del museo en solo tres semanas 35 mil personas visitaron la muestra (Pizarro 30). Tan positiva fue la recepción de la obra de Lurçat que coleccionistas privados compraron obras, y dos de los treinta tapices expuestos fueron adquiridos por el MAC tras el cierre de la muestra: C'est l'Aube (Es el alba) y Le Bouc Empetre (Macho cabrío enredado) ingresaron a la colección del museo en 1955. ${ }^{4}$ De modo paralelo, ese mismo año el Museo Nacional de Bellas Artes (MNBA) también realizó una exposición sobre la obra del artista. ${ }^{5}$ Se podría sugerir, entonces, que la tapicería y el extraño y fascinante repertorio iconográfico de la obra de Lurçat eran familiares para el público asiduo a dos de los principales museos de Santiago.

Janus, la obra donada al Museo de la Solidaridad más de quince años después de ese primer contacto con el público chileno, forma parte - al igual que el resto del trabajo textil de Lurçat - de la tradición pictórica asociada a la fabricación de tapices, en donde el tejedor se concentra en la trama y no en la urdimbre del tejido (Phipps 76). ${ }^{6}$ A partir de un diseño previo realizado en un cartón, los artesanos-tejedores reproducen la imagen previamente creada por el artista, transformando o interpretando con las fibras las modulaciones de volúmenes, luces y sombras. A diferencia de otras técnicas - la tapicería andina, por ejemplo-, el tapiz tiene un derecho y un

\footnotetext{
Simone Lurçat trabajaba, de hecho, como Oficial de Enlace Regional (d'Hauterives).

Al respecto, ver las fichas razonadas de las obras de Lurçat escritas por Gonzalo Arqueros (Catálogo razonado 378-381).

Ver las fichas razonadas previamente citadas para la historia de exhibición de Lurçat en Chile.

Es necesario mencionar que algunos de los textiles de Lurçat, sobre todo los más tempranos, son bordados y no corresponden al tejido en faz de trama.
} 
revés. Si en el anverso se puede observar la imagen representada, por el reverso los saltos de los hilos quedan a la vista. Esta condición refuerza la comprensión de estos textiles como obras bidimensionales, dependientes de la arquitectura y pensados para ser colgados de una pared. De dimensiones pequeñas, en comparación a los grandes tapices del artista que hasta el día de hoy se encuentran en Aubusson, esta obra de formato vertical representa a un gallo - un animal que figura recurrentemente en el repertorio iconográfico de Lurçat- que domina el plano del tejido. El fondo del tapiz es negro y los colores del animal - rojos, verdes, ocres y dorados - resaltan por contraste y se introducen a partir de patrones decorativos repetitivos. La paleta de colores y los patrones decorativos utilizados para dar cuenta de su plumaje son llamativos, pero es la cabeza del pájaro la que más sorprende: el rostro, antropomorfo, enfrenta al espectador. La cabeza se completa con dos perfiles adicionales de gallo que parecen dibujarse a cada lado de la cara humana del animal.

Si volvemos al título, podemos tratar de encontrar ahí una posible respuesta al enigma de este pájaro tricéfalo. Janus, en el mundo romano, era el dios de las puertas, de los pasajes, del tiempo, de los principios y los términos, del pasado y del presente, y se lo representaba con dos caras: una mirando hacia el pasado y la otra hacia el futuro o, también, hacia afuera y hacia adentro. ${ }^{7}$ Si bien el gallo no es el animal tutelar de Janus, en siglos posteriores el dios romano fue asociado a San Pedro, quien tiene las llaves de las puertas del cielo. El gallo, de hecho, es uno de los animales que acompañan al apóstol: su canto anuncia la resurrección de Cristo. El gallo era, también, en el contexto de la Francia revolucionaria, el símbolo de la libertad. En ese sentido, no es incorrecto considerar que tanto la obra de Lurçat como la que Joan Miró pintó para el Museo de la Solidaridad, en este caso, de modo dirigido e intencional, representen, cada uno a su modo, gallos. Si volvemos a Lurçat, se podría argumentar que Janus visualiza de modo contemporáneo los diálogos iconográficos entre el mundo clásico y el medieval. Asimismo, la materialidad de la obra refuerza, desde un punto de vista técnico y enraizado en la recuperación de la tradición de la tapicería francesa, la utilización del repertorio iconográfico del artista. Haciendo eco al doble o, en este caso, triple rostro del Janus tejido por Lurçat, este texto propone mapear brevemente dos momentos o umbrales de la vida de esta obra en relación con la historia del Museo de la Solidaridad: los primeros meses de vida de la institución en el contexto de la Unidad Popular, y la posterior existencia (encubierta con respecto a su lugar de origen) de la obra en Chile tras el golpe de Estado en $1973 .^{8}$

7 En algunas variaciones de la iconografía de Janus fuera del mundo romano, el dios es representado con tres caras. Para mayor información acerca del simbolismo y significado de Janus, ver Cirlot 258.

8 Para revisar los distintos periodos de la historia del museo, ver Zaldívar, 40 Años; Zaldívar, MIRSA 1975-1990. 


\section{De cara al pasado: Janus en el Museo de la Solidaridad}

Janus llegó justo a tiempo para la primera exposición del museo, en mayo de 1972 (Museo de la Solidaridad, Donación). La obra se exhibió junto a los envíos de artistas argentinos, cubanos, españoles, estadounidenses, franceses, ingleses, italianos, mexicanos y uruguayos. ${ }^{9}$ Entre los medios que se destacaron en esta primera exposición se encontraban, principalmente, la pintura y las artes gráficas y, en menor medida, la escultura. El único tapiz que formó parte de la muestra y, en términos más generales, el único textil que integró la colección de lo que hoy se conoce como el periodo "solidaridad" del museo (es decir, de 1971 a 1973), es la obra de Lurçat. Desde el punto de vista de su materialidad, la obra es única. ${ }^{10}$ Vale mencionar, por lo mismo, que más de 200 obras participaron en la muestra. Aun cuando el tapiz de Lurçat fue fotografiado y apareció en reiteradas ocasiones en la prensa como parte del material gráfico destinado a difundir la iniciativa, con la excepción de menciones específicas a la obra (nombre del autor, técnica), no se escribieron textos extensos y detallados que reseñaran esta o cualquier otra obra en particular.

Con la perspectiva que otorga el tiempo, es interesante considerar cómo una obra como Janus se insertaba en la colección del Museo de la Solidaridad, una institución que en sus bases se proyectaba como un "museo de arte moderno y experimental”. ¿En qué medida la obra de Lurçat era moderna y experimental? ¿A qué debates disciplinarios y del arte moderno apelaba la obra de Lurçat en Chile? Como comenté con anterioridad, Lurçat fue una figura paradigmática en relación con el resurgimiento de la "tapicería pictórica". Sin embargo, la agenda del artista era divergente con respecto a una de las posturas centrales del arte textil de la primera mitad del siglo xx, el constructivismo. Asociado al taller textil de la Bauhaus, "en el tejido, el Constructivismo se expresó de modo directo en un alejamiento de las representaciones pictóricas realizadas en hilo, como la tapicería pictórica" (Gardner Troy 113). ${ }^{11}$ Uno de los temas centrales del constructivismo, que comulgaba con el paradigma del modernismo, era la atención al medio artístico, en este caso, a las características intrínsecas de los materiales y de la estructura tejida. Para los artistas del constructivismo, el trabajo y la postura de un artista como Lurçat era opuesta al programa modernista que proponía la independencia de los medios artísticos: en este caso, el textil no solo estaba subordinado a la pintura, sino, también, a la arquitectura. Lurçat, sin embargo, sostenía que el textil era “[...] superior a la pintura por sus cualidades intrínsecas —era monumental, arquitectónico, intensamente colorido

9 La exposición fue de mayor envergadura en relación con el listado de obras presentado en el catálogo. El documento menciona que faltó integrar "la nómina correspondiente a la donación de los artistas de países socialistas que comprometieron su obra" (Museo de la Solidaridad, Donación).

10 Si se considera el inventario del museo hasta el día de hoy, la obra de Lurçat sigue siendo el único tapiz.

11 "[i]n weaving, Constructivism was expressed in a fairly straightforward shift away from pictorial representations in thread, such as pictorial tapestry". La traducción es propia. 
y naturalmente cálido y con textura- características que no podían ser logradas en pintura" (Gardner Troy 164). ${ }^{12}$ Su postura supone, tal como Virginia Gardner Troy ha propuesto - aun cuando no hay consenso acerca de este juicio-, una vía curiosa e interesante al interior de la historia del textil modernista (164).

Lo cierto es que Lurçat y su círculo, compuesto por otros artistas colaborando con los talleres de Aubusson - y fundamentalmente Marie Cuttoli, mecenas, coleccionista y dealer de tapices-, actualizaron la tapicería francesa. Esta actualización estaba asociada con una mirada consciente e intencionada hacia el pasado, la que buscaba reconectarse con lo que él y otros asumían como la época dorada de esta técnica: la Edad Media. A propósito de una exposición organizada en 1946 por Lurçat y por el crítico de arte, escritor y poeta Jean Cassou, titulada Tapisserie française du moyen age tous a nos jours, los curadores proyectaron la muestra como una "estrategia de apropiación del pasado que ponía el acento en la manualidad y en el espíritu comunitario asociado al 'tiempo de las catedrales" y vieron en la tapicería "un verdadero antídoto contra las derivas materialistas e individualistas del capitalismo industrial" (Froissart y van Tilburg 130). ${ }^{13}$

La mirada hacia la "época de las catedrales" de Lurçat no estaba disociada de la práctica. Al contrario, su trabajo innovó de modo específico en el proceso de diseño de una tapicería pensada y proyectada de acuerdo con el sistema de producción artesanal. "A partir de 1930, Lurçat introdujo una nueva e innovadora forma de realizar los cartones de la tapicería", a través del carton numéroté: "sus dibujos [...] limitaban la paleta de colores que utilizaban los tejedores, la que consistía principalmente en formas planas [...] [sus] cartones parecían diagramas numéricos o esquemáticos en blanco y negro, con números que indicaban los colores a ser usados" (Buckley 85). ${ }^{14} \mathrm{Tal}$ y como se ha mencionado en la bibliografía sobre el tema, a pesar de sus innovaciones el método de trabajo de Lurçat no hacía sino mantener y ahondar las diferencias existentes entre la figura del artista - individual y autoral - y la del artesano - anónima, manual y subordinada a la noción de utilidad-. Esta distinción también estaba implícitamente asociada a las diferencias que el artista establecía entre el diseño o dibujo y el tapiz.

A partir de la breve información aquí presentada, es posible comprender el porqué del éxito de la exposición de Lurçat en 1954 y 1955. Sería verosímil sugerir que la muestra en el MAC y luego en el MNBA haya estimulado una reflexión profunda sobre

12 "[...] superior to painting because their inherent qualities—-monumental, architectural, intensely hued and naturally warm and textural—could not be achieved in painting". La traducción es propia.

13 “[... stratégie d’appropriation du passé qui met l'accent sur la manualité et l'esprit communautaire associés au 'temps des cathédrales" y vieron en la tapicería el "véritable antidote aux dérives matérialistes et individualistes du capitalisme industriel [...]”. La traducción es propia.

14 "Starting in 1930, Lurçat introduced an innovative new means of creating tapestry cartoons", a través del "carton numéroté", "his drawings [...] limited the color palette that was to be utilized by the weavers, and consisted mostly of flat forms. Lurçat's cartoons resembled numbered diagrams or schematics in black and white, with numbers indicating the colors to use". La traducción es propia. 
las prácticas artísticas textiles, particularmente las cultivadas al alero de la Escuela de Artes Aplicadas de la Universidad de Chile. ${ }^{15}$ Hacia mediados de la década de 1950, se impartían dos talleres asociados a la disciplina: el de telar, a cargo de Margarita Johow, y el de gobelinos, dirigido por el francés Pierre Peytoureaux. Este último enseñaba en la Escuela de Artes Aplicadas desde 1944 (Castillo 173). Si bien investigaciones recientes, como las de Eduardo Castillo, han iluminado la historia de la Escuela de Artes Aplicadas y, también, de la Escuela de Artes y Oficios, contribuyendo de modo ejemplar a la creación de un campo que aúne intereses relacionados al desarrollo de los oficios, las técnicas, la formación disciplinar del diseño y sus vínculos con las artes, todavía está pendiente investigar de modo específico los talleres que formaban parte de esas instituciones, en donde se produjeron obras, productos y reflexiones (fueran ellas formales o informales), acerca de las prácticas, técnicas y materiales que los definían. Ese es el caso del taller de gobelino y el de telar.

Más allá del impacto que puedan haber tenido los tapices de Lurçat en la década del cincuenta, lo cierto es que la enseñanza de las artes aplicadas - y, por ende, del textil- se había transformado hacia inicios de la década del setenta. Tras la Reforma Universitaria implementada en 1968 durante el gobierno de Eduardo Frei Montalva, bajo la dirección del exrector de la Universidad de Chile, Juan Gómez Millas, la Escuela de Artes Aplicadas fue desapareciendo tras varios cambios de programas y de sede, con posterioridad a la separación de las escuelas de Bellas Artes y de Artes Aplicadas (Rivera Scott 391). Junto a la Reforma, es necesario considerar también que el triunfo de la Unidad Popular contribuyó a transformar el modo de concebir la práctica artística, produciéndose un desplazamiento hacia la cooperación y la horizontalidad, entre otros aspectos. $\mathrm{Al}$ respecto, un par de ejemplos paradigmáticos corresponden a la participación de artistas como Eduardo Martínez Bonati, José Balmes, Gracia Barrios, Roser Bru, Roberto Matta, Félix Maruenda y las bordadoras de Isla Negra, entre otros, en el proyecto del edificio construido para alojar la conferencia de la UNCTAD III - que en algún momento fue pensado para ser la "casa" del Museo de la Solidaridad-. Otro ejemplo, más decisivo aún respecto a las prácticas colaborativas, fue la exposición Las 40 medidas de la Unidad Popular; realizada en el MAC en 1971, el proyecto consistió en el trabajo coordinado de artistas, asociaciones barriales, gremiales e independientes con el fin de producir, de modo conjunto, las obras de la muestra. En este contexto, si bien la obra de Lurçat apelaba al trabajo colectivo y mancomunado del taller, al mismo tiempo recordaba la verticalidad asociada a la jerarquía y diferencia existente entre el "maestro" y los "artesanos".

No conocemos los juicios de valor, estéticos e ideológicos de la comisión organizadora (CISAC) del Museo de la Solidaridad con respecto al Janus de Lurçat, aunque

15 Un ejemplo de lo ya mencionado es la práctica de la artista Ana Cortés. Ver la ficha escrita por Gloria Cortés sobre el tapiz Músicos (Músicos de Albert Hall) en Catálogo razonado 178-179. 
sí estamos al tanto de la opinión que un personaje tan influyente como Neruda tuvo del “tapicero de genio". A pesar del cambio de paradigma artístico, la obra debió haber sido recibida con entusiasmo: Jean Lurçat era un artista de trayectoria, formaba parte de un círculo selecto de artistas comunistas, pero también era un artista reconocido a nivel local. Esto último era particularmente importante, puesto que la donación del Janus debe haber generado interés incluso en un público ideológicamente opuesto al proyecto (siempre y cuando la obra se separara del "artista comunista" que la había diseñado). Se podría pensar, de hecho, que Janus actuó en esos primeros momentos al interior del Museo de la Solidaridad como una obra "bisagra" que atraía a públicos que se encontraban en veredas políticas opuestas. Un ejemplo interesante de mencionar con respecto a este último punto tiene que ver con una nota de prensa, firmada por Ana Helfant y publicada el 2 de mayo de 1973 en Revista Ercilla (Helfant). Contraria a la UP, pero sin poder desconocer el trabajo cultural y artístico desarrollado a la fecha, Helfant decía:

Aunque en la introducción a la exposición, su presidente, el crítico brasileño Mario Pedrosa, advierte que es con motivo de la "hora de la marcha al socialismo", no todos los artistas donantes son adictos a ella. Algunos mantienen celosamente su independencia política, tanto en sus compromisos personales como en su arte. Estos artistas colaboraron con el museo por una verdadera simpatía hacia Chile, mientras otros ayudaron más por el interés político, o — como se ha sugerido también - por una "orden de partido".

Un par de líneas después, Helfant criticaba la desorganización y caos en el que estaba envuelta la formación del museo (desorden del que la misma comisión organizadora estaba consciente, dada la premura y la intensidad del trabajo, y la inexistencia de una política cultural que avalara y diera estructura a las donaciones de los artistas). Con la intención de reprobar el aspecto más débil del museo, Helfant mencionaba la preocupación de la viuda de Lurçat, quien hacía unos meses,

de paso por Santiago, se preocupó de saber qué ocurría con el tapiz donado por su marido. Sin embargo, pocos sabían dónde se guardaban las obras. La señora de Lurçat siguió indagando hasta que pudo dar con el paradero del tapiz".

Janus, sin embargo, se encontraba en el MAC, la institución en donde probablemente lo encontró su viuda. Exactamente en el mismo lugar en el que quedó junto a otras obras de la colección del Museo de la Solidaridad tras el golpe de Estado del 11 de septiembre de 1973. 


\section{El pasaje oscuro: Janus durante la dictadura}

A diferencia de algunas obras de la colección del Museo de la Solidaridad que se perdieron de vista debido a problemas administrativos, o a que simple y llanamente fueron destruidas o robadas en los días posteriores al golpe, el Janus de Lurçat corrió mejor suerte. Para el 11 de septiembre, el tapiz se encontraba en los depósitos del MAC. Casi un mes antes del golpe, hacia el 20 de agosto, se desmontó una exposición de las obras del Museo de la Solidaridad (las exposiciones iban mostrando las remesas de obras que llegaban al museo desde el extranjero), en donde había sido nuevamente incluido el Janus (Nómina de obras). ${ }^{16}$

No existen reportes de esos años acerca del estado de conservación de la pieza, pero un inventario sin fecha confeccionado por el MAC (producido probablemente durante la segunda mitad de los ochenta) indica no solo que la pieza se encontraba en buen estado, también, y más importante aún, que la obra, avaluada en dos millones de pesos, ahora formaba parte de la colección del maC (Inventario MAC). Hoy se sabe que unos días después del golpe, los funcionarios del MAC que adherían al proyecto de la up resguardaron cuidadosamente las obras de la colección del Museo de la Solidaridad (Vidal, "El arte como ejercicio"). Tiempo después, las obras fueron inventariadas como parte de su propia colección. ${ }^{17}$ Vale mencionar que la Universidad de Chile, institución de la cual dependía el MAC, fue drásticamente intervenida tras la instauración del régimen militar. De modo involuntario, entonces, el patrimonio artístico del museo creció con obras de origen diverso que habían sido donadas con un fin político específico. Con el tiempo, el público general comenzó a olvidar esas obras "solidarias" y el museo pasó al olvido. Para los que recordaban el proyecto, por otro lado, la historia de la institución se fue desdibujando de a poco, el desconocimiento acerca del paradero de las obras y la destrucción y ocultamiento de documentos contribuyó a ese proceso - tal como comenta Claudia Zaldívar en su tesis de licenciatura dedicada a la reconstrucción de su historia ("Museo de la Solidaridad. Memoria")—.

La vida artística-cultural del MAC se reanudó una vez que las autoridades del museo (y de la universidad) fueron reemplazadas por individuos afines al nuevo orden político. La efervescencia cultural y experimental que caracterizó al periodo de la UP devino en una limpieza o, más bien, vaciamiento ideológico, y en la creación de una

16 Es interesante señalar que en esa exposición se presentaron, uno junto al otro, los dos "gallos" del museo. El de Miró y el de Lurçat (Museo de la Solidaridad, "Respaldo de los artistas" 5).

17 El equipo de archivo del mssa comenta, al respecto, lo siguiente: "el proceso de inventario fue conducido por Eduardo Ossandón, que antes de ser nombrado director de modo oficial en enero de 1974, le fue encargada la tarea de hacer el inventario completo de las existencias en la colección del MAC, que incluían en ese momento a las obras del Museo de la Solidaridad. No obstante haber sido inventariadas en el mismo proceso, las obras del Museo de la Solidaridad estaban identificadas, y durante 1974 y 1975 estuvieron bajo atento escrutinio de Nena Ossa en la Oficina de Asuntos Culturales de la Presidencia, que sabía que eran un patrimonio delicado". Agradezco a Federico Brega, María José Lemaitre y Caroll Yasky la aclaración sobre este punto. 
idea conservadora, monolítica y sin fisuras de las nociones de "patria" y chilenidad. ${ }^{18}$ Por esa razón, es particularmente interesante entender cómo las obras del Museo de la Solidaridad fueron exhibidas y comentadas durante la dictadura. En ese sentido, tal vez uno de los momentos más productivos para pensar la obra de Lurçat - y de otras obras que corrieron la misma suerte que el Janus - es una exposición realizada en mayo de 1985 en el Instituto Cultural de Las Condes, titulada Exposición internacional de plástica contemporánea. El comité de selección de la muestra estaba formado por Francisco Javier Court (director del Instituto Cultural de Las Condes), Dolores Mujica (directora del MAC), Ricardo McKellar (coleccionista), Enrique Solanich (director del Departamento de Teoría e Historia del Arte de la Facultad de Artes de la Universidad de Chile) y Waldemar Sommer (crítico de arte del diario El Mercurio), todos alineados con el programa cultural promovido por la dictadura.

El evento tenía un objetivo de "contingencia": al evaluar los daños provocados en el MAC a causa del terremoto de marzo de 1985, se tomó la decisión de cerrarlo por un periodo. ¿Qué mejor, entonces, que "sacar las obras del museo" y organizar una exposición en Las Condes? Una extraña alianza era esta — una que permitía, de modo claro y directo, desplegar estrategias de reapropiación ideológica y simbólica-. En el catálogo de la muestra, Enrique Solanich escribió un texto breve pero decidor (Exposición Internacional). Aun cuando la exposición incluía obras de artistas abiertamente comprometidos con la izquierda como Joan Miró, Oswaldo Guayasamín, Roberto Matta y David Alfaro Siqueiros, entre otros, no se hacía referencia alguna a elementos que recordaran las tramas sociopolíticas en las que estaban insertas las obras y sus artistas, junto a los contextos de producción, circulación y recepción de las obras. Convirtiendo la historia del arte en una suma de eventos consecutivos que responden a movimientos artísticos predeterminados, para Solanich las obras eran imágenes sin cuerpo y sin densidad material y conceptual, que permitían el desarrollo de una historia lineal y evolutiva, centrada de modo exclusivo en los problemas formales del arte. ${ }^{19}$

Solo tres textiles participaron en la muestra y los tres pertenecían a Lurçat: además del Janus, se incluyeron los dos tapices que fueron comprados por el MAC en 1955, C'est l'Aube y Le Bouc Empetre. En el texto, Solanich le dedicó un pequeño párrafo al artista, en el que decía:

La reivindicación de las artesanías, referidas a la manufactura de gobelinos, se recrea en simbiosis de sueño y realidad en el francés Jean Lurçat al recuperar las tradiciones técnicas de la época medieval, permitiendo a la tapicería su vigencia y autonomía hasta hoy (Exposición Internacional).

18 Al respecto, ver el documental Pinochet y sus tres generales (2004) del director español José María Berzosa. 19 He desarrollado este argumento en extenso en de la Maza, "Historias". 
La aproximación de Solanich a la obra de Lurçat, especialmente en relación con la "simbiosis de sueño y realidad", hacía eco a las palabras que Waldemar Sommer escribió reseñando la muestra —en la que participó integrando el comité organizador-: Insertas en el surrealismo, estética que ha conseguido para Chile tanto fruto, surgen piezas fundamentales del actual conjunto expuesto. Así, la hermosura casi rupestre de un vigoroso Joan Miró se complementa bien con las sutilezas espaciales y las vertiginosas síncopas lineales de Roberto Matta, dueño de casa que preside la muestra. Por otro lado, dos franceses: un grabado de André Masson y el figurativismo onírico de Jean Lurçat. En su grabado y en sus tapicerías magníficas asoman briosos modelos medievales.

En su texto, Sommer siguió la misma estrategia de Solanich y redujo las obras de Matta, Masson, Miró y Lurçat a imágenes hermosas, sutiles y oníricas, productos de las subjetividades recias y masculinas de sus autores (vigor y brío son los adjetivos que más destacan en la cita). Sin dejar de hacer notar la importancia de estos artistas para la historia del arte, y subrayando, también, la condición patriarcal del arte y sus relatos, Sommer y Solanich los despolitizaron. Gracias a la dirección otorgada por ambos autores, las obras de estos artistas serían admiradas principalmente por su fuerza y belleza, y la lectura que prevalecería de ellas estaría enfocada de modo exclusivo en destacar el rol que sus autores tuvieron en el desarrollo del arte moderno.

Es posible que el comité de selección de las obras no haya pensado en las repercusiones asociadas a la exhibición de las obras del antiguo Museo de la Solidaridad. Al presentarlas, sin embargo, se hicieron nuevamente visibles piezas que habían desaparecido de la esfera pública hacía más de diez años. La lista de obras y los comentarios y frases dedicados a las mismas en el catálogo de la exposición, y en las críticas publicadas en El Mercurio, permitían constatar que las obras aún existían. Permitían, asimismo, cotejar la información que algunos actores del mundo artístico de la Unidad Popular tenían sobre el Museo de la Solidaridad. El pasado irrumpió en la inauguración de la muestra cuando el periodista cultural y crítico de arte, Ernesto Saúl, confrontó al entonces decano de la Facultad de Artes, Fernando Cuadra:

[...] le preguntamos por el origen de los cuadros. La respuesta fue breve y categórica: "Yo descubrí la existencia de esas obras. En un noventa por ciento forman parte del patrimonio del Museo de Arte contemporáneo y no habían sido exhibidas nunca". Insistimos: ¿Adquisiciones o donaciones? Respuesta del Decano: "Adquisiciones" (22).

La nota de Saúl, aparecida con posterioridad a otras notas de prensa que también se preguntaban por el origen de las obras, iba acompañada por una pequeña entrevista a Lautaro Labbé, artista y director del MAC hacia 1973, y a la fecha director de la Asociación de Pintores y Escultores de Chile (APECH), quien podía constatar el origen de las obras, "tomando como punto de partida el inventario del Museo [MAC], que 
estaba al día en 1973 y, por otro lado [haciendo] un inventario de las obras del Museo de la Solidaridad, que no tienen nada que ver con el MAC" (Saúl 22). ${ }^{20}$ A Cuadra le habría ido mejor si hubiese alegado el desconocimiento del origen de las piezas. Cualquier persona con sentido común habría podido hacer un cálculo relativo a los precios estimados de las obras en el mercado internacional, lo que habría revelado de inmediato la imposibilidad del MAC de contar con una colección como la que el decano de la Facultad de Artes decía tener.

Una consecuencia no menor de la exposición fue la salida del alcalde de la $\mathrm{Mu}-$ nicipalidad de Las Condes, Carlos Correa. Si bien eran varias las quejas de "ciertos uniformados" a la labor de Correa, una de las razones que se mencionaban en la prensa para explicar por qué se le había solicitado la renuncia, tenía que ver con la falta de tino al "exhibir cuadros del pintor ecuatoriano Guayasamín, abiertamente crítico de Pinochet" ("La salida de Correa"). Vale la pena mencionar que Guayasamín seguía vivo hacia 1985; Miró, Picasso y Lurçat ya habían muerto. ¿Cómo habría sido la recepción de la exposición si se hubiese visibilizado la biografía de esos "artistas comunistas" en oposición al discurso elaborado por Sommer y Solanich? Más allá de las especulaciones, sería interesante conocer cuál fue la evaluación interna de la comisión organizadora al cierre de la muestra: no solo habían logrado reavivar el interés y el deseo de justicia asociado a las obras del Museo de la Solidaridad, sino que también contribuyeron, simbólicamente, a la destitución del alcalde de Las Condes.

La exposición de 1985 fue un antecedente importante que permitió visibilizar la historia del museo y las consecuencias del desmantelamiento de este singular proyecto artístico-político. Después del cierre de la muestra, las obras volvieron al MAC, lugar en el que se mantuvieron hasta después del plebiscito que decidió, tras 17 años de dictadura, la vuelta al orden democrático. En 1991, en la que sería una de las primeras iniciativas por comenzar a dar un nuevo cuerpo a la colección del Museo de la Solidaridad, se realizó una exposición en el MNBA en donde las obras que se encontraban en el MAC fueron pedidas en préstamo. En una primera selección el Lurçat no fue incluido, pero el acta de préstamo incluyó una "petición expresa de la Sra. Isabel Allende" para sumar el Janus a la muestra (Acta de préstamo). ${ }^{21}$ Ese fue el comienzo de una serie de exposiciones en las que participó la obra de Lurçat, que buscaron recuperar la historia del museo y de su colección. ${ }^{22}$ La transición a la democracia supuso, para el Janus y para tantas otras obras, el comienzo de un

20 Una nota de prensa en revista Hoy también se preguntaba por el origen de las obras incluidas en la exposición (“Museo de la Solidaridad. ¿Y las obras, dónde están?").

21 Curiosamente, el acta de préstamo evidenciaba el alza en el avalúo de la obra de Lurçat. El inventario anteriormente citado del periodo de dictadura avaluaba la obra en dos millones de pesos, y en 1991 el monto había subido a tres millones.

22 Por ejemplo, la exhibición de una selección de las obras francesas de la colección en el Instituto Francés de Cultura en Santiago en 1993, la muestra del Palacio Vergara en Viña del Mar en 1994 y otra organizada por la División de Extensión Cultural del Ministerio de Educación en conjunto con la Municipalidad de Talca, presentada en dicha ciudad en 1996. 
nuevo ciclo, uno marcado por la evaluación del pasado, la recuperación de un proyecto artístico y museal innovador, y la reconstrucción de múltiples historias fragmentadas. Un proceso que, si bien ya no podía reconstruir la fuerza y vitalidad del tejido social del pasado, al menos podría mantener, de cara al futuro, el recuerdo vivo de los hilos solidarios que por un tiempo breve lograron crear una trama social, artística y política viva.

\section{Referencias}

Acta de Préstamo. Facultad de Artes Universidad de Chile, 30 de agosto de 1991, Archivo del Museo de la Solidaridad Salvador Allende, Fondo Democracia, registro g0007.

Castillo, Eduardo. "La Escuela de Artes Aplicadas en la educación chilena”. Artesanos, artistas, artífices. La Escuela de Artes Aplicadas de la Universidad de Chile 1928-1968, Ed. Eduardo Castillo. Santiago, Ocho Libros, Pie de Texto, 2010.

Catálogo razonado colección Museo de Arte Contemporáneo Facultad de Artes Universidad de Chile. Santiago, Museo de Arte Contemporáneo, 2017.

Cirlot, Juan Eduardo. Diccionario de símbolos. 9ª ed. Barcelona, Labor, 1992.

D’Hauterives, Arnaud. “Allocution prononcée par M. Arnaud d'Hauterives, Secrétaire perpétuel de l'Académie des Beaux-Arts, à l'occasion des obsèques de Mme Simone Lurçat". Saint-Laurent Les Tours, 30 de marzo de 2009. Disponible en: https://www.academiedesbeauxarts.fr/sites/default/files/inline-files/lettreacademie-des-beaux-arts-la-donation-lur\%C3\%A7at.pdf

Acceso: 4 de septiembre de 2018.

De la Maza, Josefina. "Historias homogéneas, críticas discontinuas: la historia del arte chilena en tiempos de dictadura”. XXXv Coloquio Internacional de Historia del Arte. Continuo/discontinuo: los dilemas de la historia del arte en América Latina, Ed. Verónica Hernández Díaz. Ciudad de México, Instituto de Investigaciones Estéticas, publicaciones digitales, 2018. Disponible en: http://www.ebooks. esteticas.unam.mx/items/show/51. Acceso: 4 de septiembre de 2018.

"Exposición de Jean Lurçat". Revista de Arte, Instituto de Extensión de Artes Plásticas, Universidad de Chile, agosto de 1955, pp. 26-27.

Exposición Internacional de Plástica Contemporánea en el Instituto Cultural de Las Condes. Corporación Cultural de las Condes, mayo de 1985.

Fontaine, Georges, Germain Bazin y René Huyghe. Exposición Jean Lurçat. Santiago, Museo de Arte Contemporáneo de la Universidad de Chile, 1954.

Froissart, Rossella y Merel van Tilburg. "De la tapisserie au Fiber Art: crises et renaissances au Xx ${ }^{\mathrm{e}}$ siècle”. Perspective Actualité en histoire de l'art, 1-2016, 30 de junio de 2016. doi:10.4000/perspective.6313. 
Gardner Troy, Virginia. The Modernist Textile. Europe and America 1890-1940. Aldershot, Lund Humphries, 2006.

Helfant, Ana. "El pincel solidario". Revista Ercilla, n. ${ }^{\circ} 1972.2$ de mayo de 1973.

IAL (Instituto de Arte Latinoamericano de la Facultad de Artes, Universidad de Chile). Inventario correspondiente a la segunda remesa de obras donadas al Museo de la Solidaridad. 10 de Mayo de 1972, Archivo del Museo de la Solidaridad Salvador Allende, Fondo Solidaridad, registro e0282.

Ilustre Municipalidad de Viña del Mar, Museo de Bellas Artes Palacio Vergara. Museo de la Solidaridad Salvador Allende. Selección de obras, Abril-Mayo 1994, 9 de abril de 1994, Archivo del Museo de la Solidaridad Salvador Allende, Fondo Democracia, registro g0384.

Instituto Francés de Cultura. Selección de Obras Francesas del Museo de la Solidaridad, 1 de diciembre de 1993, Archivo del Museo de la Solidaridad Salvador Allende, Fondo Democracia, registro g0185.

Inventario MAC - Museo de Arte Contemporáneo, ca. 1980, Archivo del Museo de la Solidaridad Salvador Allende, Fondo Resistencia, registro e0290.

"La salida de Correa". Qué pasa, 11 de julio de 1985, copia disponible en el Archivo del Museo de la Solidaridad Salvador Allende, Fondo Resistencia, registro d0082.

Macchiavello, Carla. "Una bandera es una trama”. 40 años Museo de la Solidaridad por Chile. Fraternidad, arte y política 1971-1973, Ed. Claudia Zaldívar. Santiago, Museo de la Solidaridad Salvador Allende, 2013.

“Museo de la Solidaridad ¿Y las obras dónde están?”. Hoy, n. 414, 24 al 30 de junio de 1985.

Museo de la Solidaridad Salvador Allende. Listado Bienes Nacionales, enero de 2004, Archivo del Museo de la Solidaridad Salvador Allende, Fondo Democracia, registro f0714.

Museo de la Solidaridad. Donación de los artistas del mundo al gobierno popular de Chile. Santiago, Quimantú, 1972.

"Museo de la Solidaridad: Respaldo de los artistas del mundo a la revolución chilena". La Nación, 22 de abril de 1973, p. 5.

Nómina de obras que se expusieron en el MAC sede Quinta Normal. 20 de agosto de 1973, Archivo del Museo de la Solidaridad Salvador Allende, Fondo Solidaridad, registro s0280.

Phipps, Elena. Looking at Textiles. A Guide to Technical Terms. Los Ángeles, The J. Paul Getty Museum, 2011.

Pinochet y sus tres generales. Dirección y guión de Mario Berzosa, fotografía de Maurice Merrimond, INA, Francia, 2004.

Pizarro, Andrés. “Cómo se formó el Museo de Arte Contemporáneo de la Quinta Normal”. Revista de Arte, Instituto de Extensión de Artes Plásticas, Universidad de Chile, n. ${ }^{\circ}$ 3, mayo de 1956, p. 30. 
“Recuento gráfico de las artes plásticas durante 1972”. La Nación, 7 de enero de 1973, p. 8 Rivera Scott, Hugo. "Arte y modernidad en torno a la Escuela de Artes Aplicadas". Artesanos, artistas, artífices. La Escuela de Artes Aplicadas de la Universidad de Chile 1928-1968, Ed. Eduardo Castillo. Santiago, Ocho Libros, Pie de Texto, 2010. Saúl, Ernesto. "El museo extraviado". Pluma y Pincel, n. ${ }^{\circ}$ 16, julio de 1985, pp. 20-22. Sommer, Waldemar. "Siglo xx: Abandono y encuentro de lo reconocible". El Mercurio, 5 de mayo de 1985.

Teitelboim, Volodia. Neruda. Santiago, Sudamericana, 2003.

Ugarte Eléspuru, Juan Manuel. “12 meses de artes plásticas en Lima”. Anuario Cultural del Perú 1954, Lima, 1955, pp. 47-53

Vidal, Virginia. "El arte como ejercicio de la libertad”. Anaquel Austral (blog), 21 de mayo de 2014. Disponible en: http://virginia-vidal.com/publicados/ensayos/ printer_566.shtml. Acceso: 4 de septiembre de 2018.

Zaldívar, Claudia. "Museo de la Solidaridad. Memoria para optar al grado de Licenciado en Teoría e Historia del Arte”. Departamento de Teoría e Historia del Arte, Facultad de Artes, Universidad de Chile, 1991.

--. Editora. 40 años Museo de la Solidaridad por Chile. Fraternidad, arte y política 1971-1973. Santiago, Museo de la Solidaridad Salvador Allende, 2013

-_. Editora. Museo Internacional de la Resistencia Savador Allende, MIRSA 19751990. Santiago, Museo de la Solidaridad Salvador Allende, 2017. Libro en formato electrónico.

Enviado: 29 de octubre de 2018

Aceptado: 29 de septiembre de 2020 